\title{
A CONSTRUCTIVIST APPROACH TO ONLINE TRAINING FOR ONLINE TEACHERS
}

\author{
Dr. Sanford Gold \\ FDR Station PO Box 1268 \\ New York, NY 10150 \\ Email: sholom_gold@yahoo.com
}

\begin{abstract}
This article examines the pedagogical role of the teacher in online education. Specifically, the transition from in-class room instruction to online instruction is a complex one involving specialized training in the technical aspects of delivering quality educational materials (or environments) to the students, and specialized training in how to foster knowledge acquisition within this new environment. The article focuses on the pedagogical training that an online instructor needs to become an effective teacher.

The article investigates a two-week faculty development pedagogical training course aimed at preparing teachers to operate effectively within an online educational environment. In attempting to orient the teacher to the online environment, the course used a constructivist instructional methodology within an online context. Several types of collaborative exercises were employed such as virtual field trips, online evaluations, interactive essays, and group projects.

The sample $(\mathrm{N}=44)$ represented veteran college teachers with little online teaching or studying experience. Tenured faculty (30\%) and Instructors (25\%) composed the majority of the class. The group had well over 13 years classroom teaching experience (53\%), and over three-quarters are currently teaching in higher education institutions.

Hypotheses were tested through online data collection and surveys to find out the effects of the pedagogical training on the participants. One important finding of the study concludes that teachers exposed to the course significantly changed their attitudes toward online instruction seeing it as more participatory, and interactive than face-to-face instruction. Another major finding is that after the course, teachers saw the online medium as more of an extension of their faculty work. That is, faculty were more willing to use the online medium as an extension of their duties.
\end{abstract}

KEYWORDS: constructivism, faculty development, pedagogical training

\section{INTRODUCTION}

One of the affordances of the new online learning movement is the opportunity it presents to reexamine the ways in which some aspects of traditional instruction can be re-conceived to operate effectively in the online asynchronous environment. This technological shift-from knowledge being fixed to a certain time and place, to knowledge being accessible at anytime and at anyplace - creates the potential for a change in the way learning is transacted from those who provide information (i.e. teachers or facilitators) to those who receive it (i.e. students).

The author's claim is that teachers must have the actual experience of online learning before they can be expected to be online teachers; otherwise, they simply map traditional practices onto the new medium with little of the transformation necessary in the teaching process. This transference from what is known to work well in one medium to another is not a choice as much as a pre- 
condition. Without proper pedagogical training and online experience, teachers will continue to replicate their best existing practices onto the online medium. This divergence between what works in the traditional classroom within a stable cohort of learners communicating synchronously face-to-face is qualitatively different from an online asynchronous one.

The mere fact of a technological change does not guarantee educational transformation or reform; this is no fait accompli. While this new movement has the potential to alter the traditional student-teacher relationship and improve learning outcomes, changes in educational delivery do not in themselves cause any significant impact upon learning outcomes of the students. [1] Many reasons are cited for this failure: extraordinary cost of implementation, lack of infrastructure to support implementation, lack of quality curriculum materials, inadequate professional training, and more.

It seems apparent that successful educational technological reform requires the consent of the faculty, as shown by the fact that past forms of technology, radio, film, television, and video have failed to radically change the way education has been delivered and transacted. [2] In other words, even though technology may change the way students learn, it will have no impact without teacher support, and one of the most important reasons for the lack of faculty support is lack of faculty preparation. Teachers must be trained in using this new technology.

Technology training can be viewed in two different ways: the first is in the use of the technology to create and implement learning environments (i.e. online courses) for students to learn the knowledge domain circumscribed by the author-creator. The other is the ability to instruct within the learning environment created - in other words, the facilitation of content to the student via the Web in an asynchronous format. Though face-to-face teachers (teachers in conventional classrooms) currently perform both these functions, they are qualitatively different tasks, and knowing one well does not presuppose knowing how to do the other well. [3] Developmental training is different from pedagogical training. It is the author's contention, that for teachers to teach effectively online they need to have had an online learning experience.

This article focuses on the training of teachers of higher education by means of a two-week workshop- "Teaching on the Web: A Nuts and Bolts Approach"-in online pedagogy and facilitation techniques. This workshop is used as the intervention to examine what the effects are of being an online learner on future online teachers.

Within instructional design, two major instructional frameworks have emerged - objectivism and constructivism. Simply stated, within objectivism, the designer sets the performance objectives and creates a systematic approach to the learning content. The instructor's role is to teach the students a well-circumscribed body of information within a well-defined learning environment. [4] Constructivism is less content-oriented and more learner-centered; the designer goal is to create an information-object rich, and socially meaningful (i.e. communication and collaboration filled) learning environment. The facilitator aides the learner through the creation of authentic tasks and helps the student integrate other understandings of multiple perspectives through reflection. [5] This study is aimed at assisting existing faculty members, who have little or no online experience, create an understanding (and practice) of constructivist online pedagogy. The training is intended to provide them with the ability to customize learning content for students and facilitate their ability to construct knowledge.

The online teacher training class was offered from Feb. 1- 12, 1999 and was the sixth version of a class originally created in the Fall of 1998. The course employed a discussion-centric structure, and used a constructivist methodology to convey the future changes an online teacher will be expected to make in order to be effective. A variety of online individual and class projects were created.

Forty-four participants were exposed to the course. Seven hypotheses were tested:

1. The extent to which respondents rethought their teaching practices was related to the 
increase in exposure to the course.

2. The extent to which attitudes towards various aspects of online teaching and learning was related to the increase in exposure to the course.

3. The extent to which factual knowledge increased was related to increase exposure to the course.

4. The number of respondents who indicate that online distance learning courses should be part of regular faculty work was related to increase exposure to the course.

5. The amount of additional monetary compensation respondents required to teach online will decrease was related to increase exposure to the course.

6. The number of respondents who would apply for grants (or monies) to take teacher training programs for teaching online distance learning courses was related to increase exposure to the course.

7. The number of respondents who indicate that online distance learning training courses like this one should be required of all current and future teachers was related to increase exposure to the course.

\section{CASE FOR CONSTRUCTIVIST ONLINE EDUCATION}

The late 1950s, 1960s, and 1970s saw the growth of behaviorist thought and systems analysis. Instruction could now be programmed by following a series of stages to guide student instruction and evaluation. These early forms of computer-aided instruction (CAI) centered on tasks that produced easily quantifiable errors, like exams. This made assessment a simple quantitative exercise by computer systems. Content was seen as stimulus, which produced desirable behavioral changes (i.e. learning) in the student-user. It was thought that given enough iterations students would eventually make no more errors, and, hence "know" all there is about the information contained within the computer program.

In the last few decades, the rise of the microcomputer, advances in cognitive psychology, and online connectivity have emerged as the leading forces in education reform as education goes online. The popular edict "the network is the computer" has taken hold in education as computers are able to share information with each other across time and space. Online learning is seen by many as a way to part from the past's mistakes and create a new and better form of active learning and exploration.

Despite varying degrees of success with Programmed Instruction methods, much of the online design methodologies of the present day reject its Objectivist philosophy and man-to-machine methodology. Instead of focusing on training individuals, the goal now is to educate students and help them learn better. With this shift from giving information to the passive student sitting on the other side of the screen, to engaging the student in becoming a part of the learning environment, the entire conception of online learning and design has been altered.

Constructivism is an alternative epistemology of how people learn and assimilate new knowledge. Humans are active, knowledge-searching creatures that transform and interpret experience using developed biological and mental structures. They assimilate new knowledge by producing cognitive structures that are similar to the experiences they are engaged in. They then accommodate themselves to these newly developed knowledge structures and use them within their collection of experiences as they continue to interact with the environment. [6]

Knowledge is not separate from but rather embedded within experiences and interpreted by the learner. Knowledge then is about interpretation, and making meaning of the environment. In other words, though we may more or less share one reality, each of us conceives of it in different ways 
based on our prior experiences, belief structures and perspective. To learn, therefore, is to communicate and demonstrate understanding of the world.

From this view, interpretation constructivism can include different types of knowledge construction than rote memorization of factual knowledge or procedures. The goal for the learner is to build, or re-invent knowledge. Ordering and re-ordering knowledge, testing it out and justifying this interpretation are the underlying principles of constructivist practices. [7] From a constructivist point of view, learning is a search for meaning. To make meaning, students must focus on concrete situations and understand not only the facts but also the context in which these facts are placed. Students' exposure to multiple perspectives and authentic situations enables them to combine their learning experiences and transform them into personal meaning. These meaningful structures, "schemata", are then used to interpret and create meaning when new knowledge is introduced. Learning, in this context, is the "making" of understanding by the individual.

It is beyond the scope of this article to fully elucidate the practices of constructivist teaching here. There is still much debate over what exactly is and is not constructivism, but any constructivist instruction includes three principles. [8]

1. Progress from the specific to the general, from the concrete to the abstract. [9] [10] This is the reverse of Objectivist thinking. Constructivist learning emphasizes the creation of rich, meaningful learning environments where learners can best induce the knowledge to be learned. The difficulty, frankly, is not the use of these environments when teaching new material, but incorporating the proper assessment activities that are derived from the content.

2. Actively build with and from prior assimilated structures. Only through knowing what types of learning failures and misconceptions students hold can learning be assimilated. This is done through reflection mediated by a teacher-facilitator. To achieve greater assimilation and accommodation, teachers must learn to recognize and understand the strategies students are using to perform tasks, ask questions to elicit better comprehension and reflection, and challenge the learners through facilitation procedures so students must defend their position.

3. Teach for conceptual understanding. Skills and strategies used by students are representative of some deeper, underlying understanding they possess. While practice and reinforcement are used for skill mastery, constructivism is meant for deep understanding. So, while practice should not be neglected, teachers and course content should be less about a superficial review of knowledge and more about creating new experiences. [11]

In sum, constructivist environments start with observations within a world of authentic artifacts rooted in authentic situations. Students, while accessing various materials, construct ongoing interpretations of their observations, and collaborate with their peers. Finally, students serve as coaches and teachers to each other to show their mastery of what they learned.

\section{ALN AND CONSTRUCTIVISM}

As a theoretical approach, the course employed a constructivist philosophy in its design. Researchers have pointed out the connections between the online medium and the constructivists' framework of teaching and learning. [12] [13] [14] They claim that the learning methodology is as important as the instructional technology employed. [15] There also seems to be a connection between the pedagogical tendency of the teacher and their Internet use and valuation. The more constructivist the orientation, the greater the teachers' average use of the Internet and the more positively they viewed its incorporation into instruction. [16] 
In accordance with this research, the choice of instructional design for the training course was a deliberate decision; all attempts were made not to make an online teacher training course, but to make a constructivist online teacher training course. Instead of outcome, the class facilitator focused all his energies on process and tried to facilitate the students' own ability to acquire knowledge.

\section{A. ALN and Constructivism}

What are the facilities provided by ALN that make implementing the constructivist approach more feasible? To examine this, the instructional principles of a constructivist environment need to be more rigidly defined. Piaget's processes for knowledge construction are:

- Assimilation - Associate new events with background knowledge and prior conceptions.

- Accommodation- Change existing structures to new information.

- Equilibrium - Balance internal understanding with external "reality" (e.g. other's understanding).

- Disequilibrium - Experience of a new invent without achieving a state of equilibrium. [17]

The table below maps the Piaget's four processes involved in the construction of knowledge, the principles involved and how they map to an ALN (adapted from Akyalcin, Constructivism - an epistemological journey from Piaget to Papert). [18]

Table 1. Constructivist Components within an ALN environment

\begin{tabular}{|c|c|c|}
\hline Processes & Instructional Principles & ALN Components \\
\hline Assimilation & $\begin{array}{l}\text { Gauge the learner's previous } \\
\text { knowledge and experience. }\end{array}$ & $\begin{array}{l}\text { Pre-test } \\
\text { Introductory Posts }\end{array}$ \\
\hline Assimilation & $\begin{array}{l}\text { Orient the learner to his learning } \\
\text { environment (LE). }\end{array}$ & $\begin{array}{l}\text { Broadcast Emails } \\
\text { Syllabus } \\
\text { Resources } \\
\text { To Do lists } \\
\text { Glossary } \\
\text { Course Information } \\
\text { FAQ } \\
\text { Synchronous Chat }\end{array}$ \\
\hline Assimilation & $\begin{array}{l}\text { Solicit problems from the learner } \\
\text { and use those as the stimulus for } \\
\text { learning activities, or establish a } \\
\text { problem such that the learners } \\
\text { will readily adopt the problem as } \\
\text { their own. }\end{array}$ & $\begin{array}{l}\text { Course Testing and Revision } \\
\text { Class Content } \\
\text { Synchronous Chat } \\
\text { Online Lectures and Readings } \\
\text { Non-graded, Starter Activities } \\
\text { Facilitative Questions }\end{array}$ \\
\hline Assimilation & $\begin{array}{l}\text { Support the learner in developing } \\
\text { ownership for the overall } \\
\text { problem. }\end{array}$ & $\begin{array}{l}\text { Discussion Forum feedback by } \\
\text { other students' and facilitator }\end{array}$ \\
\hline Assimilation & $\begin{array}{l}\text { Anchor all learning activities to a } \\
\text { larger task or problem. The } \\
\text { learner should clearly perceive } \\
\text { and accept the relevance of the } \\
\text { specific learning activities in } \\
\text { relation to the larger task. }\end{array}$ & $\begin{array}{l}\text { a) Individual Unit Activities } \\
\text { leading to Team Project }\end{array}$ \\
\hline Accommodation & $\begin{array}{l}\text { Design the LE to support and } \\
\text { challenge the learners' thinking. }\end{array}$ & $\begin{array}{l}\text { Modularize Content so as to } \\
\text { scaffold learning } \\
\text { Behavior Modeling by facilitator } \\
\text { Quizzes for reinforcement }\end{array}$ \\
\hline
\end{tabular}




\begin{tabular}{|c|c|c|}
\hline & & $\begin{array}{l}\text { Compare and Contrast Activities } \\
\text { Facilitative Questions } \\
\text { Discussion Forum feedback by } \\
\text { other students' and facilitator }\end{array}$ \\
\hline Accommodation & $\begin{array}{l}\text { Design the task and the LE to } \\
\text { reflect the complexity of the } \\
\text { environment in which they must } \\
\text { function after the learning has } \\
\text { occurred. }\end{array}$ & $\begin{array}{l}\text { Online Course Delivery } \\
\text { Modeling of Course Structure and } \\
\text { Components } \\
\text { Team Project }\end{array}$ \\
\hline Accommodation & $\begin{array}{l}\text { Encourage testing ideas against } \\
\text { alternative view and alternative } \\
\text { contexts. }\end{array}$ & $\begin{array}{l}\text { Discussion Forum } \\
\text { Modularize Content to introduce } \\
\text { new concepts quickly } \\
\text { Compare and Contrast Activities } \\
\text { Interactive Essay } \\
\text { Facilitative Questions } \\
\end{array}$ \\
\hline Equilibrium & $\begin{array}{l}\text { Design an authentic task. An } \\
\text { authentic LE is one in which the } \\
\text { cognitive demands are consistent } \\
\text { with the demands in the } \\
\text { environment for which the learner } \\
\text { is being prepared. }\end{array}$ & Team Project \\
\hline Equilibrium & $\begin{array}{l}\text { Provide an opportunity for } \\
\text { reflection on both the learning } \\
\text { content and process. }\end{array}$ & $\begin{array}{l}\text { Facilitator Evaluation of Team } \\
\text { Projects } \\
\text { Auto-marked Quizzes } \\
\text { Open Student Evaluation to } \\
\text { instructor }\end{array}$ \\
\hline Disequilibrium & $\begin{array}{l}\text { Provide an opportunity for } \\
\text { changing and enhancing, drafting, } \\
\text { and redrafting. }\end{array}$ & $\begin{array}{l}\text { Unit Summaries of student } \\
\text { discussions }\end{array}$ \\
\hline Disequilibrium & Challenge misconceptions. & $\begin{array}{l}\text { Students' and Facilitator's } \\
\text { Feedback } \\
\text { Project Gallery } \\
\text { Post-Test }\end{array}$ \\
\hline
\end{tabular}

\section{B. Components of a Constructivist Class}

Each of the components listed here was integrated within the course. This section outlines the course components across three areas-the curriculum content of the course, the instructional method, and the assessment and feedback mechanism.

\section{Curriculum}

Constructivism replaces the standard curriculum with solving problems within the context of a person's previous knowledge. The curriculum is the content from which and upon which reflections of understanding (i.e. ideas) are made.

Class content focused on online pedagogy and was based primarily on interviews with teachers and distance learning coordinators throughout the United States. In 1998, a series of summer online workshops on distance and online education topics that others and the author facilitated were held. These exchanges provided evidence that teachers were very interested in online education and had very little resources to help them. Participating on distance educators listserve posts, and by following various online publications, websites, journals, and conference proceedings helped define the content and its structure. Much insight was gained from the comments of David Spencer, a doctoral student at Rutgers University, who taught the course four 
times, as well as previous students who provided invaluable feedback of earlier versions of the course.

The class was broken into five units. Each unit had its own learning objectives and built upon the material from the other units. The curriculum consisted of a text lecture, and main and suggested readings. The choice of using text was a conscious decision; its ease in downloading, portability, and ability to communicate fine detail made it appropriate for this subject matter. Many of the students preferred to go through the content of the course off-line and log back on to participate in the ongoing discussion.

The class began with an orientation to instructional design and the objectivist and constructivist philosophies. By having a theoretical groundwork, students could better frame their current teaching methods. These labels allowed for discussion to focus on how to apply these philosophies, specifically the constructivist framework, to the online class. The first unit also spent time on defining what distance and online education is and is not. Definitions were extremely important and theoretical frameworks were established to provide a common framework to guide discussion.

The second Unit was concerned with the transition the teacher makes from in-class to Web class teaching. The objectives of the lesson were to understand the kinds of change that occurs in the teaching process as courses go online. The discussion began to set the stage for the teachers' future role as a facilitator and the ability to comfortably manage an online teaching and learning experience.

Unit Three built upon the end of Unit Two's discussion and went into detail about conferencing and collaboration. This Unit spanned the weekend so the material included was a bit more than the other four units. The purpose of the Unit was to learn and discuss the process and practice of online collaboration, and participate in an online collaborative exercise.

The fourth Unit showed the students how to evaluate courses using another framework besides objectivism or constructivism. The lecture contained the activity for the Unit - to choose a criterion to critique an online course, and apply this framework to two courses. The Unit's objectives were to learn to critically preview courses and apply the criteria in an evaluation activity.

The intention of the course was to convey what an online student experience was like. In the last unit, "Visualizing a New Paradigm," students were asked to examine their learning experience, and discuss the problems associated with teaching online The lecture talked about the motivations and learning styles of students and teachers, and contained a section on how teachers can deal with the special problems of online. The final section discussed how to customize an online course to pique student interest based on The Keller Motivational-Design Model.

\section{Instruction}

Instruction is the combination of subject matter with a method (and structure) to produce cognitive changes in the student. Constructivist instructors tailor their teaching strategies to the students and encourage them to interpret, analyze, and predict information. Student interaction was done via facilitative questions and recorded in the discussion forum. Facilitative questions were used as the 'stimulus to thought' and the opportunity to test ideas done in the discussion forum. These facilitative questions and the role of the facilitator-teacher made up the instructional method.

Facilitating an online class is very different from a face-to-face class. It is different because the location of the teacher is physically separate from the student, and information can be stored and transmitted across time and space. When these two conditions are not present, teachers tend to see their primary role as an information provider and transmitter. However in the online world, the 
process of knowing something and teaching may not be so intrinsically linked. This has a bearing on three factors: the dissemination of knowledge, the testing of knowledge, and the relationship between teacher and student. When using the online learning environment these three levers of teachers' control, giving information, grading, and physical intimidation are weakened.

Knowledge resources are vast online, the teacher has the ability to leverage these resources and incorporate them into his learning environment. Given the dynamic linking ability of the Internet and the reproduction of knowledge objects, instructors have the ability to choose and use a myriad of resources and tools to instruct and engage their students. The difficulty of online instruction is not in the transfer of knowledge but in creating the most apt learning environments for students to acquire this knowledge.

The evaluation of student performance vis a vis traditional testing methods can be automated online. This opens up the opportunity for online instructors to incorporate different assessment measures to gauge deep understanding of concepts across a large student body. Online courses have the ability to be simulated environments for students to practice activities within an authentic context. The transfer of skills can now be done within an environment that provides targeted feedback and is non-threatening.

Lastly, the physical absence of the teacher causes the need for other ways to create the motivational and authoritarian link between instructor and student. The anonymity of text dialogue puts more of an emphasis on explicit content rather than the physical attributes of the content (e.g. voice, gestures). Instructor dialogue therefore must be meaningful and relevant to the students' needs to have an impact on their understanding. Online instructors may also have to be more out-going, positive, and responsive to gain respect from their students.

Online teaching is not necessarily inter-linked with the act of giving information, or comparing students ability through an arbitrary grading mechanism. Contrary to prevailing practices, teaching is about the art of producing growth in another's understanding and ability. As Dewey wrote in 1916, "all that the educator can do is modify stimuli so that response will as surely as is possible result in the formation of desirable intellectual and emotional dispositions." [19] In an online class, the structure of the course becomes the representation of the instructional method, which can be modified for the students.

In this course, the structure centered around the discussion board. It became the intellectual center where spokes of discussion threads created by the participants emanated to and from the curriculum content. Through this portal, students learning took place. This never-ending discussion produced the dialogue and shared learning space that translated the content to ideas, and activities. While email was used several times within the class for broadcast messages, its use was discouraged. Beside from several technical or personal matters, all teacher-student transactions were contained within the discussion forum.

The discussion forum used was O'Reilly WebBoard, version 3.0.501, by Duke Engineering/O'Reilly \& Associates, Inc. This software is quite common in academic circles and was chosen for its ease of use and price. WebBoard uses a three-window structure. The top window was a toolbar listing several forum options. The other two windows were the messaging areas. To the left were folders where the messages were posted. For example, the class began with the Introduction folder. Within this were threads students created with their own messages using the Post button. To view the messages, students could click on and read them in the far right frame. Students could also respond to a message after it was posted. There were several options to reply. But most importantly, a student could cut and paste existing text within their next reply, to allow accurate and robust sharing of knowledge, creating meaningful, contextualbased dialogue. 
Online moderators have three fundamental roles: organizational, social, and intellectual. The organizational role involves setting the agenda for the discussion. What are the objectives, the timetable, and the rules of procedure for the discussion? Essentially, the teacher must lay the groundwork for the discussion to begin. The moderator's main social role was the creation of a friendly environment for the students. Good moderators often send out welcome messages, use a personal tone, and seed their feedback with specific examples and references. Another important social role was that of modeling good Net and intellectual behavior for the students. The best teachers often show the students how to be better students, and in turn, teachers themselves. Finally, the moderator must become the facilitator of the students' understanding. The teacher should focus on crucial points of discussions, ask questions, probe student responses, synthesize and summarize points, and help develop themes that link to the readings and class resources.

Organizationally, the course had two structures: the physical components of an online class, and the participatory habits structure of the instructor's online time. As to the first, there were two main ways for the students to navigate the class: the Syllabus Index and the To Do Lists. Posted in the left frame, these two structures provided the students with both a non-linear and linear way of progressing through the class materials.

From the Syllabus Index, the various course materials were linked. By using various font types, font sizes, and colors, students could get a macro view of the course. By macro view, the students could see and access the entire course and all the links in one Web page. There are several types of Syllabus Indexes and it took over a year of experimentation to come up with this design. The Index has four columns: Dates and To Do Lists, Web Lectures and Readings, Assignments, and Comments. Each one of these corresponds to how the material is segmented.

Table 2. Syllabus Index (abridged)

\begin{tabular}{|c|c|c|c|}
\hline $\begin{array}{l}\text { DATES and } \\
\text { TO DO } \\
\text { LIST }\end{array}$ & WEB LECTURE AND READINGS & ASSIGNMENTS & COMMENTS \\
\hline $\begin{array}{l}\text { Pre- } \\
\text { Workshop } \\
\text { Resources } \\
\text { (Optional) }\end{array}$ & $\begin{array}{l}\text { Resources Page } \\
\text { These are references for you to refer } \\
\text { to as you use the course (and } \\
\text { hereafter). Take a look; use what you } \\
\text { want. None of this is required. }\end{array}$ & Take Pre-Course Survey & Read the FAQ. \\
\hline $\begin{array}{l}\text { UNIT ONE } \\
\text { Pedagogy } \\
\text { and } \\
\text { Definitions } \\
\text { of DL } \\
\text { Feb. } 15 \\
\text { What to do } \\
\text { for today? }\end{array}$ & $\begin{array}{l}\text { Lecture One Course Creation (Case } \\
\text { Study) } 3 \text { pages. } \\
\text { Readings Main - Primer on } \\
\text { Instructional Design Theory (Part I) } \\
\text { Paper outlining objectivist and } \\
\text { constructivist theories as they relate } \\
\text { to ID. } 5 \text { pages. } \\
\text { Suggested - Definitions of Distance } \\
\text { Learning } \\
\text { What is distance learning? Review } \\
\text { some of the articles here. Which one } \\
\text { is closest to your view. Why? } \\
\text { Suggested - What's it like to teach } \\
\text { online? A diary of one woman's } \\
\text { distance learning experiences, by } \\
\text { Vicky Phillips, who began making } \\
\text { online courses in 1990. } 2 \text { pages } \\
\text { Suggested - Case studies of Online } \\
\text { Education } \\
\text { FACILITATIVE QUESTIONS }\end{array}$ & 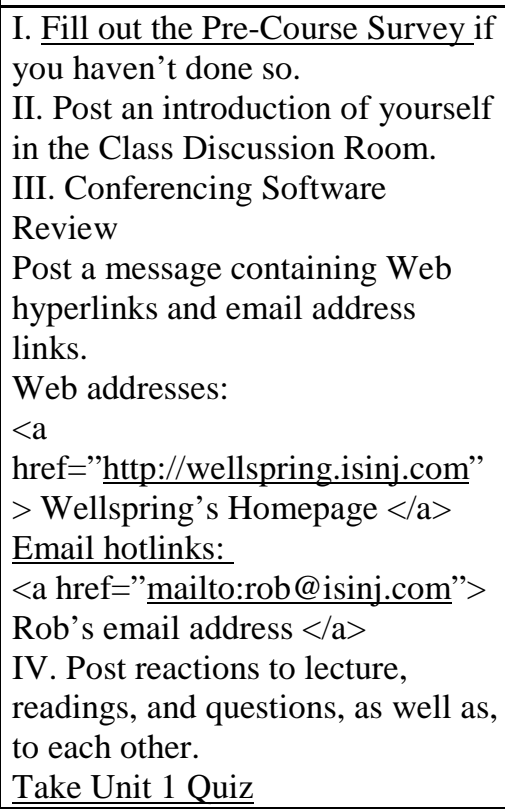 & $\begin{array}{l}\text { Welcome!! } \\
\text { Official first } \\
\text { day of class. } \\
\text { Have fun, and } \\
\text { make friends :-) } \\
\text { Read the Class } \\
\text { Information } \\
\underline{\text { Page. }} \\
\text { To find out } \\
\text { more about the } \\
\text { Project, Read } \\
\text { the } \\
\underline{\text { Assignments }} \\
\underline{\text { Page. }}\end{array}$ \\
\hline UNIT ONE & & Catch up on Unit 1 activities. & Online Office \\
\hline
\end{tabular}




\begin{tabular}{|c|c|c|c|}
\hline $\begin{array}{l}\text { Feb. } 16 \\
\text { Discussion } \\
\text { Day } \\
\text { What to do } \\
\text { for today? }\end{array}$ & & $\begin{array}{l}\text { Post a comment to another post in } \\
\text { the Forum. }\end{array}$ & $\begin{array}{l}\text { Hours Today. } \\
\text { Check the } \\
\text { Discussion } \\
\text { Forum for time. }\end{array}$ \\
\hline $\begin{array}{l}\text { UNIT TWO } \\
\text { Teaching } \\
\text { Online } \\
\text { Feb. } 17 \\
\text { What to do } \\
\text { for today? }\end{array}$ & $\begin{array}{l}\text { Lecture two Teaching Online } 4 \\
\text { pages. } \\
\text { Readings Main - Comparison of f2f } \\
\text { methods with online learning. } 5 \\
\text { pages. } \\
\text { Suggested - Best Teaching Practices } \\
\text { A more Constructivist tack on } \\
\text { Teaching On and Off-line. } 20 \text { pages. } \\
\text { Suggested - Guidelines for } \\
\text { Instructional Design A more } \\
\text { objectivist look at the good practices } \\
\text { of web-based teaching and } \\
\text { development. } 4 \text { pages. } \\
\text { FACILITATIVE QUESTIONS }\end{array}$ & $\begin{array}{l}\text { I. Surf the Web and choose two } \\
\text { online courses, one objectivist and } \\
\text { one constructivist, and post the } \\
\text { URLs in the discussion forum. In a } \\
\text { paragraph comment on the } \\
\text { pedagogical approach, and why it } \\
\text { succeeded or failed. } \\
\text { II. Post reactions to lecture, } \\
\text { readings, and questions, as well as, } \\
\text { to each other. } \\
\text { Take Unit } 2 \text { Quiz }\end{array}$ & $\begin{array}{l}\text { Partner List } \\
\text { Posted. Send e- } \\
\text { mail to partner } \\
\text { and begin } \\
\text { discussing } \\
\text { project. }\end{array}$ \\
\hline
\end{tabular}

Each row provided the students with what they should do in each section by date. Students could click on the information they needed for the date corresponding to the class. By structuring the course in this way, it was incumbent on the students to log in regularly and keep up with the class activity. Due to time limitations, however, every other day (excluding the weekend), students would begin a new Unit. This allowed for one-day discussion, and some reflection time before starting on new materials.

The To Do Lists provided a step-by-step approach to each Unit. A student who clicked on the link, "What to do for today?" would see a page listing the objectives of each Unit and what was expected of them in a linear order. The To Do Lists followed the same pattern and included a box of what objectives to learn, followed by links to the lecture, readings, questions, activities, and quiz. Students who need more of a structure and sequence of activities could go here and follow the prescribed agenda of items. A calendar view of dates in the class was included so students would not be confused about what to do when.

This navigation system was meant to be both familiar to someone who is schooled in traditional instruction, as well as compensate for the new online medium. From studies designing Web sites, users find structures (i.e. well-known metaphors) they are already familiar with to be easier to understand. [20] In an online class environment, the syllabus display provides a common touchstone for the student.

The facilitator online time was approximately two hours a day, slightly more in the beginning and less towards the end. The facilitator found it important to have a specific times of when to log on and off each day so students could have some consistency of the teacher's presence. In this case study, he read every one's post, but other facilitators who taught the class did not feel the need to do this. For the Online Instructor, facilitation should be seen as less about the teacher having a dialogue with the students and more about the students having a dialogue with each other.

The teachers' social role began even before the class officially started. "Posting an Introduction" was the first web interactivity the student engaged in. Though one does not think of class introductions as being critically important in face-to-face classes, in online ones they are crucial. 
To start off this exchange the facilitator posted his introduction several days before the class began.

The introduction included an identification paragraph, followed by professional interests, personal interests, and some words of advice. Interestingly, most students seem to use the teacher's introduction as a template for the way to post their Introductions. Online Instructors behavior is often seen as a model for students' online behavior. Online facilitators must establish certain habits and good practices early to expect the same of their students.

Online Instructors should also be encouraged to front-load their facilitation and be more active than usual early in the course to establish a caring online presence and an interest in the students. This works to create a positive atmosphere and a sense of student trust in the class. As a general rule, facilitators should try to respond to everyone's introductory messages with a reply welcoming the student in the class and asking them something about themselves. Often times this would begin an entirely new thread of conversation letting the teacher know not only about the student but also identifying characteristics with others who may share similar interests. The goal was to use the students' background information to investigate a series of topics that might be of interest to the other students in the class, creating a community of learners.

The Introductory posts are relevant to exchange ideas, share information, and create a social environment where students feel comfortable interacting with each other. The teacher can now probe certain topics to obtain a deeper understanding of students' needs beyond the pre-course survey. In this way, the discussion forum opens exchanges and expands upon the curriculum creating a successful environment for the course.

Table 3. Number of posts in the discussion forum per Unit

Posts by Unit

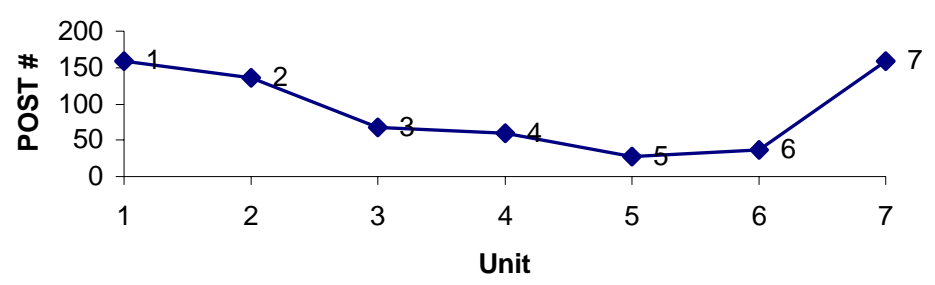

As for the class's activity, the chart shows the number of posts by Unit. According to the graph, the discussion looks as if it declined after Unit Two. This was due to attrition by those that did not feel the materials were for them, or were too busy to complete the work. When surveyed, the data clearly shows that students personal issues were most inhibitive followed by not having sufficient time needed to devote to the course itself. The technology used in the course was lowest ranked among the seven indicators.

Another interesting finding is that when the project folder (indicated by number 7 on the chart and posted throughout the class and completed on the last day of the class) is factored in, much of the activity remains fairly consistent throughout the two-week period. This would indicate that there remained a stable base of active participants throughout the conclusion of the course. From the posts, the materials and activities towards the end of the course were seen by the active students as just as important as those in the beginning. 
In terms of the quality of facilitative posts, an objective criterion to grade interactions is extremely difficult to formulate. One important indicator is how many posts are required for the instructor to be considered effective. Though, the extent to which a facilitator should post, and exactly what constitutes a quality online transaction is subjective, the circumstantial evidence revealed from this course is that online teachers take on the role of a lead learner and guide students through the information. Hiltz and Turoff estimates that online facilitators should post between 10-30 percent of the messages of the class. [21] This low percentage of teacher-student posts is indicative the shift teachers make from information source and assessor, to one who customizes learning environments to foster self-introspection and collaboration. In this course, the instructor posted 148 times out of the total 712 posts for a $21 \%$ ratio.

Finally, the course instructor found that tailoring his responses according to the students' needs created a need for students to come back to the course to make more contributions. Holding students' interest in an online class is a difficult task. Teachers must know who they are teaching, and understand their perspectives to help them learn better. To do this well requires technique, time and experience.

The facilitative questions played the role of taking the data of the course and translating it into stable content. Their purpose served as a rhetorical device to stimulate thought about the content to be used for reflection, in a style somewhere between a Zen koan and a traditional essay question. Often times, these questions led to extended and sometimes surprisingly unrelated but nevertheless significant conversations. Students learn from listening to each other with the goal of understanding another perspective. These questions were intended to provoke, not comply, thought, and they proved instrumental in focusing the discussion. By giving students a starting point, the online facilitator can better control the flow of the discussion but maintain an open atmosphere to allow for personal opinion.

\section{Assessment}

Assessment is seen as part of the learning process, where students can openly discuss and reflect on their own work and the work of others. There were four primary individual activities throughout the course: virtual field trips, online evaluations, interactive essays and a group project. The goal is for the students to immediately apply what they have learned in some context. Their understanding is revealed through their activity artifact posts in the discussion forum for comment and discussion. Since all students were required to do the same activity (with some exceptions), students can also assist each other through Zone of Proximal Development (ZPD) learning moments. Self-marked quizzes were available at the end of each Unit. Students could take them as many times as they wished until they had mastered the information contained.

According to constructivism, learning is not about producing specific outcomes, but the process by which those outcomes are produced. Products need to be evaluated within the contexts they were produced. Product assessment should also be rich and multimodal to include as many different ways of expressing meaning as possible, such as, portfolios.

Unit One's activity was to post a hyperlink and email address to the WebBoard. The purpose was to provide a skill that the student would use over and over again in the classes they compose more complex messages. This was the only technical activity in the course. Despite some initial frustrations, the overwhelming majority was successful. This learning-by-doing approach gave the students something they could contribute with little effort and provided a platform to exchange ideas.

This early success however was met with frustration when students were asked to post pictures, to the forum. Part of this trouble had to do more with WebBoard than a comment on the students' inability to post a message. The WebBoard uses unusual commands in this regard and perhaps it was a mistake to include a technical activity that the student could not accomplish. Initial 
activities should be arranged so that learning failure is low. In a larger sense, the students' frustration with the technology can be seen as part of the learning experience of the course. They had a tangible lesson in the frustrations of sharing online information. One benefit was that the technically savvy students began to help the technically disadvantaged. This spontaneous ZPD collaboration allowed for community building and shared experiences.

The activity for Unit Two was to surf the Web and choose two online courses, one objectivist and one constructivist, and post the URLs in the discussion forum. In a paragraph, the students commented on the pedagogical approach, and why it succeeded or failed. The purpose of the activity was an application of the theory learned in Unit One. In Unit Four, students repeated this activity but unlike Unit Two, they were provided with a non-pedagogical evaluative checklist, and the online courses to evaluate. The purpose of revisiting this activity was to expand the students' perspective of evaluating online courses based on a number of different criteria. Moreover, the evaluation of similar sites with a common methodology created much crosscommunication and insight among the students' themselves.

Unit Three's activity was for the class to write an Interactive Essay. An Interactive Essay is a document in which each student adds one or two paragraphs to an ongoing essay. It is a linear document that students create collaboratively at different times. Unlike the individual activities before, the purpose here was to demonstrate a group exercise that could be done asynchronously. The topic of the essay was "How to Encourage Cross-Communication and Collaboration in Online Classes."

The last activity was the class project due on the last day of the workshop. Each student was assigned to a team of three. These triads, and some dyads, worked collaboratively to create the project. The project was a Syllabus Index from an existing course, an online Principles of Biology I course. In other words, if the students were to facilitate the Biology course how would they structure the materials for their future students. The purpose of the project was for them to integrate the knowledge learned in the class and start customizing courses by using existing online material and content. All projects were catalogued in the Project Gallery. In this way, students could evaluate what others' have done with the same content. Detailed facilitator critique was given to each project.

One interesting finding about the projects is that many of the students appropriated many of the structures in the online class for their online class. This was not an unconscious aping-for each project was unique. The end result was a plethora of course structures each with constructivist practices incorporated in the design. From post-course interviews, students said that much thought and work went into the structuring of content, that is, the construction of the learners' path.

Students also discussed their collaborative experience working with their peers. In general, this work was considered quite difficult, and consumed more time than thought. Roles were not assigned to the exercise, but the students decided for themselves. In a typical case, the roles became divided according to technical abilities. Usually, the most advanced technical person was responsible for the end product, while the others provided design input.

\section{USER POPULATION}

\section{A. Background of Participants}

Users were notified of the course through online advertising and email. Any faculty without email and connection to the Internet, and a rudimentary ability to use them to respond to messages and view information, was ineligible for the study. Almost $90 \%$ of the students indicated voluntary participation. In the end, the class was well attended with 57 students on the official role; 44 
completed the pre and/or post-course survey, a 77\% completion rate. This group is the sample examined.

\section{User Profile}

The sample represented veteran college teachers with little online teaching or studying experience. The class was composed of all adults, with the largest proportion over 46 years old $(68 \%)$. Tenured faculty $(30 \%)$ and Instructors $(25 \%)$ composed the majority of the class. The participants had well over 13 years classroom teaching experience $(53 \%)$, and over three-quarters are currently teaching in higher education institutions. However, two-thirds of the class indicated they were not publicly certified teachers.

The respondents indicated a diversity of classroom subjects taught. The class subject taught most was social science (29\%), followed by other (21\%), technology-related courses (18\%), with humanities, science/math, and language courses (11\%).

Most have never taught their or other subjects online but two-thirds plan to next year. 64 percent reported they have never taught over the Net before, and 72 percent indicated that they have never been an online student before.

Almost all the teachers' institutions were from North America, and over three-quarters of this latter group were from the Northeast (15\%), Midwest (25\%), and Central (17\%) regions respectively. The number of students in the institutions served averaged between six and seven thousand students.

\section{Teachers' training needs and institutional support}

Participants were asked to rank what kinds of policies in regards to technology and training were needed within their institution. Nine policies were listed: more technical help, more instructional design support, more hardware and software, more networking of existing hardware, more Internet access, more training, better policies in general, and more research about education and technology. The ranks were not sequential, and one policy could be ranked equally with another. The need for training surfaced as the only policy these teachers ranked in the critical area. In table 4, High Need indicates the users ranked it in the top-two 50\% or more, Needed in the top-three $50 \%$ or more, and Low Need indicates more than $50 \%$ outside the top-three.

Table 4. Workshop Participants Priority For Training

\begin{tabular}{|l|l|}
\hline PRIORITY & POLICIES \\
\hline High Need & more training for teachers and students \\
\hline Needed & $\begin{array}{l}\text { more technical help, more instructional design support, more hardware, } \\
\text { more Internet access }\end{array}$ \\
\hline Low Need & more networking of hardware, more software, better policies, more research \\
\hline
\end{tabular}

\section{Teaching Experience with Computers}

Teachers were queried about their use of computers and software. Most students had a positive inclination toward technology. Over half reported they were "heavy users who (did) not feel threatened by technological change," and a third "(used) computers to replace previous methods and as classroom tools." And, despite some individual cases, the majority of the class did not seem too inhibited by the technical requirements of the class. A bit more than $40 \%$ had less than 5 years of experience, and a third had between 6 to 12 years. These teachers have an interest in computers and technology and may be considered early adopter of computers. However, twothirds of this group have never taken a course about technology and development before. 


\section{User population as a representative sample}

No data was gathered as to the technical ability of the higher education population as a whole, so it is difficult to know whether this sample is indicative of the entire population. This sample does have a built-in bias for those who know how to get online are also likely to know what to do after they are online. The technical means and ability were in fact the pre-requisites for taking the course. Given their bio-social and technical ability, these individuals are most likely only slightly above average to their North American counterparts. While highly motivated, they do not appear to be highly technically proficient. The study results, while difficult to generalize, would be most germane to a similar group with at least these minimum technical skills.

\section{DATA COLLECTION AND RESULTS}

\section{A. Data Collection}

Users were asked to complete an online survey before entering and upon finishing the course intervention. An online survey resembles a paper survey except instead of writing in the answer in a survey grid, respondents "click" or type in a box on a web page. Subjects were matched and various indicators were measured. This online survey was the quantitative measurement of the dependent variables. The survey contained series of questions that corresponded to each hypothesis. Additional questions were also asked but were not included in the study.

In general, online surveys have their problems of accuracy, validity, and reliability. Identification of who is actually taking the survey is unknown. The investigator can only trust that those who filled out the survey are who they claimed to be. To ensure accuracy, Internet Protocol addresses, $\log$ in times, and bio-social responses to match up pre and post course survey results were coded.

The issue of whether these survey measures were truly representative of the hypotheses and the course's effects is open to interpretation. Without a battery of real-time observational data how the students spent their time in the course is unknown. Discussion forum posts do provide some clues into the meaning students were producing along the way and a glimpse of their growth at each Unit.

\section{B. Hypotheses Testing and Results}

This article sets out to answer the question whether or not exposure to the course had an effect on the forty-four sampled participants. Seven hypotheses are examined to study changes in the participants' attitudes and behavior. The dependent variables were determined by the pre and post-course survey answers, and how they differed. The independent variables were the exposure to the course measurements. These measurements were: the number of self-reported hours in and outside related to the course, the number of times logging into the course, and the number of posts made to the discussion forum. Only the first measure was self-reported; the conferencing software kept a log of the number of times logging in and posting.

In analyzing the results, the relationship of the dependent to the independent variable was either done by linear regression or chi-square tests. The first measures the pre and post course means and sees if the variables of number of times logged in, the number of times posted to the discussion forum, or the number of total hours spent in and outside the class have any effect, that is, a significant change in the mean. The other measure does not explain causal relationships. It simply states that the distribution frequency of the data has been changed. Both are valid only if the results are below the .05 level.

Table 6. Descriptive Statistics of the Independent variables

\begin{tabular}{|c|c|c|c|c|c|}
\hline & $\mathrm{N}$ & Minimum & Maximum & Mean & $\begin{array}{c}\text { Standard } \\
\text { Deviation }\end{array}$ \\
\hline
\end{tabular}




\begin{tabular}{|c|c|c|c|c|c|}
\hline Posts & 44 & 0 & 38 & 11.77 & 11.07 \\
\hline Hours & 44 & 1 & 70 & 19.34 & 14.40 \\
\hline Logins & 44 & 1 & 127 & 27.97 & 32.07 \\
\hline
\end{tabular}

The seven hypotheses tested are as follows:

\section{Hypothesis 1 - The extent to which respondents rethought their teaching practices was related to the increase in exposure to the course.}

The extent to which respondents rethought their teaching practices was positively related to the increase in exposure to the course. The purpose of this course was to do precisely what this question asked. This hypothesis was tested based on students answer to one survey question. From 0 (not at all) to 10 (very much), please rate the extent to which this class helped you rethink your teaching practices?

Using a linear regression model, comparing the dependent variable (mean= 5.74, $\mathrm{SD}=3.71$ ) to the three independent variables, the results indicate a highly significant change in the sample's rethinking their teaching. The results are at the .000 level and the over half the variance ( $\mathrm{r}$ square $=.531$ ) is explained by these three indicators. This confirms that the two-week intervention was successful in its aims of having teachers reexamine their ways of teaching when faced with the online medium. Total hours of exposure are the strongest indicator (partial $\mathrm{p}=.007$ ), and more time students exposed themselves to the course and related materials, the stronger the effect.

Comparative changes in teachers' philosophies are difficult to assess in a two-week intervention, and the author does not claim that the course fundamentally changed teachers' approach to instruction. No pre-course data measuring teaching philosophies was gathered. However, qualitative data from the discussion board, students' posts, and materials generated, and the result of hypothesis 2 indicate that the shift was more in line with constructivist methodology.

\section{Hypothesis 2- The extent to which attitudes towards various aspects of online teaching and learning was related to the increase in exposure to the course.}

The extent to which attitudes towards various aspects of online teaching and learning was positively related to the increase in exposure to the course. To study attitudinal change, the investigator devised a 17 -item likert scale ranging from strongly disagree to strongly agree. The first series of measures were about communication and level of interaction; the second were about the teachers' structure and control over the course and its outcomes. The next was about the teachers' use and performance, then, a series about property rights, and lastly, training. This scale was created to investigate if any of these individual measures changed rather than any general consensus about the indicators as a whole.

Each attitude indicator, that is the difference between pre and post individual attitude means, was compared. Out of the 17 attitudes, three proved to be significant to the .05 level in a paired sample test. They were:

Online distance learning courses encourage more student participation than traditional face-toface courses. $(\mathrm{p}=.005)$

Online distance learning teachers and students can produce learning outcomes better than traditional face-to-face teachers and students. $(\mathrm{p}=.013)$

Online distance learning courses have more student-to-student interaction than traditional face-toface courses. $(\mathrm{p}=.014)$

This finding is interesting and helps define what type of rethinking was taking place. Rethinking may be seen more in the direction of increased student participation and interaction. This confirms many of the constructivist principles and practices demonstrated in the course. Students 
believed that learning outcomes derived from these practices were also efficacious. This finding provides additional validation of the course and its objective.

\section{Hypothesis 3 - The extent to which factual knowledge increased was related to increase exposure to the course.}

The extent to which factual knowledge increased was positively related to the increase in exposure to the course. The previous findings showed that the students were significantly affected by the experience, this hypothesis examines whether or not they gained any factual knowledge. This hypothesis measured whether more exposure to the course would lead to higher answers on a multiple-choice quiz. To study factual knowledge gain or loss, a 15-item scale of multiplechoice questions relating to online learning and teaching was created. These questions were asked in pre- and post-test questionnaires. By this method, two measures were obtained and differences could be found.

The linear regression with the dependent variable differences between pre- and post-score means yields an insignificant result $(\mathrm{p}=.088, \mathrm{r}$ square= $=149)$. The results are insignificant. Hours of exposure do give the best result (partial $\mathrm{p}=.122$ ) but clearly do not rise to the level of importance.

However, another test was done. This measure examined whether the frequency of the distribution of pre and post scores significantly changed, that is, shifted higher (or lower). Using a paired sample t-test, these results are highly significant $(\mathrm{p}=.000)$. The mean difference scores (pre $=4.68$, post mean $=8.16$ ) shifted upward signaling an increase in knowledge gained.

This shift is not completely explained by the course intervention. This means that the three measures, total hours, logins, and posts, do not explain the full treatment effects. Perhaps, exposure to the course may not have resulted in all the learning gain. The course was not designed to teach for the test. And to be fair to the participants, many of the answers to the test questions were buried in the suggested readings.

Some critics of constructivist courses often cite the sacrifice of content acquisition to the process of learning. While no such conclusions can be drawn here, the course was focused more on process and experiential learning than cognitive gains. In as much as this factual knowledge was important, the ultimate "purpose" of the course was not to earn a high score on the final exam, but to produce a learning artifact within a community of other learners. Given the discussion posts around the project, and the quality of submissions judged by the instructors and other students, the construction of knowledge by practice was not captured by the results of the instructor's test of factual information.

Hypothesis 4 - The number of respondents who indicate that online distance learning courses should be part of regular faculty work was related to increase exposure to the course.

The number of respondents who indicated that online distance learning courses should be part of regular faculty work increased after completion of the course. This hypothesis investigated whether students felt that online teaching was in any way connected to their traditional teaching role. This hypothesis tests whether the course would have the effect of bringing the two teaching worlds, face-to-face and online, together. The question used to investigate this change was: Should teaching online distance learning courses be a part of regular faculty work? The difference in mean scores pre and post were compared to produce the dependent variable. Using a chi square test, a significant result was found (Chi Square $=.036$ ). The results can also be seen by the means of those who switched from before the course, indicating it was different from regular faculty work, to after the course, indicating it was the same as regular faculty work. The average means of the "different" group is 16 hours of course exposure while the "same" is 24 . The six people that switched were exposed over 22 hours, higher than average. 
These results point to the integration of the online teaching experience with the traditional one. Teachers who have more training feel as if the online world is an extension of their job, and not something unique or alien. These findings concur nicely with the Taylor and White survey (1991) of an Australian University's faculty attitudes toward distance learning, and Pierpoint and Hartnett study (1988) of American programs, which concluded that the art of teaching and interpersonal interaction were highly valued in job satisfaction. [23] [24].

Lonsdale indicates current faculty reward structures show an over-reliance on extrinsic rewards (i.e. support or consequence coming from the university administration, including financial incentives for teaching online) and a lack of congruence between the established reward mechanisms and intrinsic motivation. Intrinsic motivation is characterized by the desire to participate in an activity where the reward is the act of participation itself. [25] Schifter's survey (1999) of a Research I state related institution indicate that faculty may be more inclined to intrinsic factors when participating in ALN than most administrators perceive. [26]

\section{Hypothesis 5 - The amount of additional monetary compensation respondents required to teach online will decrease was related to increase exposure to the course.}

The amount of additional monetary compensation respondents require to teach online decreased after completion of the course. This hypothesis examined whether teachers felt that they deserve more money for teaching online learning courses. The question asked was: If monies were given to you, would you teach online distance learning courses (in \$500 intervals)? Respondents were asked to indicate a dollar figure in 500-dollar intervals. An upward shift would signal that teachers see the online experience as something arduous, and needed of more compensation. A shift downward may signal a closer equating of the online teaching as an extension of their existing job and not in need of additional compensation. Using a chi square test, the pre and post figures were compared and found to be significant (Chi Square $=.046$ ).

This result translates into a decrease from $\$ 1975$ (pre-class compensation) to $\$ 1675$ (post-class compensation). This confirms the result that teachers see their online role in a similar context as their regular one. This "new teaching" is part of their old roles, and institutions may not need to provide an extraordinary amount of extra financial compensation. This conclusion also validates the financial importance of teacher training programs. It is this increase in comfort using the technology from experience and control in understanding how the medium can be used to deliver effective education. This result should be seen within the context of the previous hypotheses that teachers see online course as part of their regular work.

These results validate recent studies of faculty views towards extrinsic versus intrinsic rewards. Two mid-west university faculty surveys indicated that financial incentives were comparatively not as important as support issues. [27], [28] Betts' research indicates that institutional policies are important to attracting faculty to and retaining faculty in distance education. Institutional policies, Betts and other experts claim, largely determine the extent to which faculty use technology as an instructional tool. These experts advise that faculty be fully involved in the policy-making process from the start. [29]

The following two hypotheses were insignificant:

\section{Hypothesis 6 - The number of respondents who would apply for grants (or monies) to take teacher training programs for teaching online distance learning courses was related to increase exposure to the course.}

The number of respondents who would apply for grants (or monies) to take teacher training programs for teaching online distance learning courses did not significantly increase with more exposure to the course. The question asked was: Would you apply a grant (or monies) to take teacher-training programs for teaching online distance learning courses? Despite eight 
respondents switching after taking the course, this finding was not significant (Chi Square $=$ $.054)$.

\section{Hypothesis 7 - The number of respondents who indicate that online distance learning training courses like this one should be required of all current and future teachers was related to increase exposure to the course.}

Prior to the course, the author asked a series of questions to see what kind of training their institutions are providing, and how it is delivered.

Table 7. Workshop Participants Training Experience And Needs

\begin{tabular}{|l|l|l|l|l|l|}
\hline SURVEY QUESTIONS & No & Yes & $\begin{array}{l}\text { Yes, face to } \\
\text { face }\end{array}$ & $\begin{array}{l}\text { Yes, } \\
\text { online }\end{array}$ & $\begin{array}{l}\text { Yes, either type of } \\
\text { delivery }\end{array}$ \\
\hline $\begin{array}{l}\text { Does your Institution have a formal } \\
\text { training program in technology and } \\
\text { online course development }\end{array}$ & $74.4 \%$ & $25.6 \%$ & & & \\
\hline $\begin{array}{l}\text { Have you ever taken a course in } \\
\text { technology and online course } \\
\text { development }\end{array}$ & $65.8 \%$ & $34.2 \%$ & & & \\
\hline $\begin{array}{l}\text { Do you want to take a course in } \\
\text { technology and online course } \\
\text { development }\end{array}$ & $2.6 \%$ & na & $5.1 \%$ & $30.8 \%$ & $61.5 \%$ \\
\hline $\begin{array}{l}\text { Does your Institution have a formal } \\
\text { training program in teaching online }\end{array}$ & $94.9 \%$ & $5.1 \%$ & & & \\
\hline $\begin{array}{l}\text { Have you ever taken a course in } \\
\text { teaching online }\end{array}$ & $76.9 \%$ & $23.1 \%$ & & & \\
\hline $\begin{array}{l}\text { Do you want to take a course in } \\
\text { teaching online }\end{array}$ & $5.3 \%$ & na & $0 \%$ & $31.6 \%$ & $63.2 \%$ \\
\hline
\end{tabular}

These results clearly show the gap between teachers' needs and institutions perceptions or capabilities. While the overwhelming majority of the sample wanted to take a course in technology and development (97\%), online teaching (95\%), their institutions are currently providing neither (74\% and $95 \%)$.

The number of respondents who indicated that online distance learning training courses like this one should be required of all current and future teachers did not increase significantly after completion of the course. Over 30 out of 36 users believed that a class like this was important. However, offering a class like this one solely online was not significant (Chi Square $=.808$ ).

When given a choice between face-to-face or online, however, most of these teachers clearly want online courses. A little less than a third of the sample preferred this method prior to taking the class. While the results did not show an increase after the online course, this is not to imply that participants prefer classroom instruction either. Given the need for the course, perhaps many participants were satisfied in having one at all, regardless of the delivery medium.

\section{CONCLUSION}

In summary, results indicate that the teachers shifted towards a more constructivist orientation, valuing increased interaction and communication. Along with this change, teachers also gained some knowledge about distance education. This combination of content and experience provides dual reinforcement validating the course experience.

After exposure to the course, the respondents felt that online courses offered more student participation than traditional face-to-face courses, and that online courses have more student-tostudent interaction than traditional face-to-face courses. Moreover, teachers saw the online medium as more of an extension of their faculty work. That is, teachers saw teaching as their job 
and teaching online consistent with their role as an instructor. This would indicate that the central issue for the future of teachers is more about training and less about the correct reward structures. Institutions should take note that as their faculty force becomes more empowered using this online medium; they will want to use it. After all, teaching is sometimes referred to as a calling more than a regular vocation, and strong inner motivations need to be valued and recognized.

The workshop's integration of method and medium is, the investigator claims, the primary reason for the positive results in changes in teachers' attitudes and thinking about educational practice. This reexamination of existing practices and adoption of ones more appropriate to the online learning environment is one of the affordances (i.e. change catalyst) of the Internet.

According to William Perry, thinking is a developmental process beginning from duality, moving to an understanding of multiple views, and finally acknowledging the context wherein the solution is given-weighing circumstantial evidence alongside factual data. [30] This shift from pure reason and information from determining "correct" answers to a consideration of self, situation, previous experience, and thinking strategies in creating "appropriate" answers is in essence the shift from objectivist to constructivist pedagogy.

These findings buttress this corporatist, constructivist view of learning as contributing to deeper understanding that may affect behavioral change. From posted messages, activities, and surveys, the data showed that the ability to connect with others' knowledge and experiences, as well as, their feedback is essential.

Another important finding of the study is the re-orientation of the teacher to the online world as something 'out there' to something within the domain of their regular duties. Post-course data indicate that respondents saw online teaching as part of their job, and decreased their need for external incentives. These results point to the value of providing adequate training. Perhaps after a training experience that provides an orientation to the technology and the way it can be employed, institutions will need not to rely as much on external incentive structures to coerce certain faculty groups to adopt online teaching. The ability to function (i.e. teach effectively) in the online world, and the nurturing of internal incentives, should be strongly considered when institutions draft policies regarding online technologies and faculty.

Constructivist-based teacher training courses may be a vehicle to stimulate the intrinsic motivations of classroom-based faculty members as they go online to teach. Jaffee points to the importance of "pedagogical hooks" as an important source for this faculty transformation and change. By positing alternative online strategies that help motivate students and allay some of the problems associated with face-to-face training (e.g. silent classrooms), he concludes that faculty may gain a greater acceptance of the online modality. Indeed, the pedagogical methodology may be the area where faculty define their "core professional identity" and not the physical location wherein they practice the method. [31] The author claims that if online pedagogies can support those characteristics of a rewarding instructional experience, faculty will be more likely to embrace the medium.

Online case studies, like the one examined, have three major limitations: sample size constraints, inadequate methods to capture online behavioral data, and inability to distinguish long-term effects. First, increasing the size of the study's sample is not as simple as allowing more students into an online course. Though not fixed and dependent on technological, experiential, and methodological factors, there does seem to be an upper boundary of the number of students one facilitator can support in a constructivist framework. To do this well, teachers must understand the cognitive strategies of their students and know how best to structure content, that is, know what to do when to facilitate learning. While debatable, the estimates surveyed for maximum online class sizes in a constructivist online learning environment are somewhere between six and 30. The fact that 44 students were studied in this article, and many more came and went within 
the two-week period, is quite higher than this range. Whether one agrees with this or not, online teacher experiences have shown how time consuming an online facilitating experience can be, even when building a class to support large populations. If more students were added into the class than the facilitator can support, the instructional method employed has a greater possibility of corruption.

When researching the effects of the impact of an instructional method, researchers may want to consider providing a standard number of cohorts, and replicating the study across facilitator teams. Though no data was collected, this course was replicated with about two dozen students using three different facilitators. These iterations helped to refine the instructional method eventually examined. By using different facilitating methods, certain best practices could be revealed, and through an evolutionary process of trial and error, knowledge of what works best with what kinds of students could be discovered.

The second issue is the ability to capture online behavioral data. In this case study, online observation techniques were employed. Unlike traditional methods, online observation involves some trust on the part of the observer that accurate, valid, and reliable measures are captured. As an online researcher, one must assume that all comments and work done by the student were actually performed by him or her. If a student were to "cheat," as an observer, one would have a difficult time discovering the misinformation. The course used a firewall to protect access from outside intruders, so any "errors" would be only the results of students' sabotage.

An online course can be a deep reservoir of student behavioral data. By viewing the experience from the students' perspective, teachers' choices of instructional methods and objectives vis-à-vis the media and technology used may reveal a prescription of teaching practices that are subject to quantitative scrutiny. It can also provide great insight into the course structure and methods used. Do certain course methods/structures support certain knowledge acquisition pathways? Can multiple course structures customized to support students' learning strategies within a similar set of learning objectives be built?

Lastly, the inability to distinguish long-term effects is a major limitation of the case study reported. A two-week intervention is a relative short time to affect behavioral change to longstanding practices. No data was gathered of teachers' pedagogical practices prior to entering the course, and no follow-up study was done upon their exiting. This isolated, concentrated view of behavioral change indeed may be enervated over time.

Though this case study did not perform a longitudinal study, researchers are encouraged to consider implementing pre-course and post-course analytical tools to study behavioral change and persistence. Data regarding teachers' off-line and online teaching methods and instructional strategies used, the amount of teacher-student and student-student interactions, the use and customization of content within the medium, and their assessment and reward mechanisms all may provide indications of pedagogical changes. This data will help in knowing how long term training classes need be to provide adequate support for traditional faculty and whether the training programs had the desired effect.

\section{REFERENCES}

1. Russell, T. The "No Significant Difference" Phenomenon as reported in 248 Research Reports, Summaries, and Papers Fourth Edition. North Carolina: North Carolina State University. Web address: http://teleeducation.nb.ca/phenom/

2. Cuban L. Teaching and Machines. New York: Teachers College Press, 1987.

An expert in a knowledge domain does not presuppose he or she is an excellent teacher. The skills of research and publication are different than the skills of teaching. 
3. McManus, T.F. "Delivering Instruction on the World Wide Web, University of Texas at Austin," 1996. Web address: http;//ccwf.cc.utexas.edu/ mcmanus/wbi.html

4. Mekhalfi, A. "Constructivism," 1997. Web address: http://seamonkey.ed.asu.edu/ mcisaac/emc703old97/spring97/7/mekh7.htm

5. Flavell, J.H., Cognitive Development, $3^{\text {rd }}$ ed., New Jersey, Prentice-Hall, 1993.

6. Black, J.B. \& McClintock, R.O.. An interpretation construction approach to constructivist design. In B. Wilson (Ed.), Constructivist learning environments, New Jersey, Educational Technology Publications, pp. 25-32, 1996

7. Fosnot, C.T. Center for constructivist teaching/teacher preparation project. Paper presented at the Association of Teacher Educators' Annual Conference, Orlando, FL. 1992.

8. Karmiloff-Smith, A. \& Inhelder, B. If you want to get ahead, get a theory. Cognition, 3, pp.195-222, 1974.

9. Piaget, J. The development of thought: Equilibration of cognitive structures. New York, Viking Press, 1977.

10. Jonassen, D.H. Evaluating constructivist learning. In T.M. Duffy \& D.H. Jonassen, Constructivism and the technology of Instruction, New Jersey, Educational Technology Publications, pp. 137-148, 1992.

11. Arminio, J. The virtual campus: Technology and reform in higher education. Journal of College Student Personnel, 40(1), 114, Spring, 1999.

12. Sprague, D. \& Dede, C. Constructivism in the classroom: If I teach this Way, am I doing my job? Learning and Leading with Technology, 27(1), 6-9, 16-17. September, 1999.

13. Turoff, M. Education, commerce, communications: The era of competition. WebNet Journal; 22-31. January-March, 1999.

14. Ibid.

15. Becker, H.J. "Internet Use by Teachers: Conditions of Professional Use and TeacherDirected Student Use," Center for Research on Information Technology and Organizations. February 1999. Web address: http://www.crito.uci.edu/TLC/findings/Internet-Use/startpage.htm. An initial result of an ongoing study of the Teaching, Learning and Computing survey research of secondary school teachers $\left(4^{\text {th }}-12^{\text {th }}\right.$ grades $)$. According to their publication, "later reports will discuss pedagogical differences among different groups of teachers and will provide data on specific aspects of teachers' beliefs and practices."

16. Piaget, J. The development of thought: Equilibration of cognitive structures. New York, Viking Press, 1977.

17. Akyalcin, J. Constructivism - an epistemological journey from Piaget to Papet, June, 1997. Web Address: http://www.kilvington.schnet.edu.au/construct.htm

18. Dewey, J. Democracy and Education. New York, The Free Press, 1916.

19. Nielsen, J. Designing Web Usability: The Practice of Simplicity, USA, New Riders Publishing, 2000.

20. Hiltz, R. \& Turoff, M. Education, Commerce, and Communication: The Era Of Competition, 1997. Web address: http://eies.njit.edu/ hiltz

21. Bess, J.L. (ed.). Teaching Well and Liking It, Baltimore, The Johns Hopkins University Press, 1997.

22. Pierpoint, P.E. \& Hartnett, R.A. Faculty attitudes toward teaching in off-campus graduate programs. International Journal of Innovative Higher Education; 5 (1), 25-30, 1988.

23. Taylor, J.C. \& White, V.J. Faculty attitudes towards teaching in the distance education mode: An exploratory investigation. Research in Distance Education; 7-11, 1991.

24. Lonsdale, A.. Changes in incentives, rewards, and sanctions. Higher Education Management, 5. 223-235, 1993.

25. Betts, K.S. Factors influencing faculty participation in distance education in postsecondary education in the United States: An institutional study. Doctoral dissertation, The George Washington University, 1998. 
26. Schifter, C.C. Faculty Participation in Asynchronous Learning Networks: A Case Study of Motivating and Inhibiting Factors, Journal of Asynchronous Learning Networks, Vol. 4, No. 2, June, 2000.

27. Rockwell, S.K, Schauer, J., Fritz, S.M., \& Marx, D.B. Incentives and Obstacles Influencing Higher Education Faculty and Administrators to Teach via Distance, Online Journal of Distance Education Administration, Vol.2, No. 4, Winter, 1999.

28. Rockwell, S.K, Schauer, J., Fritz, S.M., \& Marx, D.B. Faculty Education, Assistance and Support Needed to Deliver Education via Distance, Online Journal of Distance Education Administration, Vol.3, No. 2, Summer, 2000.

29. Cross, K.P. Open Windows on Learning. The Cross Papers 2. League for Innovation in the Community College, June 1998.

30. Jaffee, D. Institutionalized Resistance to Asynchronous Learning Networks, Journal of Asynchronous Learning Networks, Vol. 2, No. 2, September, 1998.

\section{ABOUT THE AUTHOR}

Sanford Gold is Project Manager in the Distance Learning Department at Prudential Securities University. He holds a M.Ed. in Instructional Technology, and an Ed.D. in Politics and Education from Teachers College, Columbia University. His current research interests include: linking competency models to employee development, creating a value chain model for private knowledge exchange, and developing constructivist learning object architectures. 